Portland State University

PDXScholar

\title{
The Demand Driven Acquisitions Pilot Project by the Orbis Cascade Alliance: An Interview with Members of the Demand Driven Acquisitions Implementation Team
}

Jill Emery

Portland State University, jemery@pdx.edu

Follow this and additional works at: https://pdxscholar.library.pdx.edu/ulib_fac

Part of the Library and Information Science Commons Let us know how access to this document benefits you.

\section{Citation Details}

Emery, Jill, "The Demand Driven Acquisitions Pilot Project by the Orbis Cascade Alliance: An Interview with Members of the Demand Driven Acquisitions Implementation Team" (2012). Library Faculty Publications and Presentations. 52.

https://pdxscholar.library.pdx.edu/ulib_fac/52

This Post-Print is brought to you for free and open access. It has been accepted for inclusion in Library Faculty Publications and Presentations by an authorized administrator of PDXScholar. Please contact us if we can make this document more accessible: pdxscholar@pdx.edu. 
The Demand Driven Acquisitions Pilot Project by the Orbis Cascade Alliance: An Interview with Members of the Demand Driven Acquisitions Implementation Team

Jill Emery, Contributor

The Orbis Cascade Alliance (the Alliance) team started planning for a consortia-wide demand driven acquisitions (DDA) pilot project for ebooks with 36 participating libraries, YBP, and EBL in January 2011. The news release can be found here:

http://www.orbiscascade.org/index/demand-driven-acquisitions-pilot . 1 The initial meetings involved: setting the parameters for the pilot project, designing the workflow to be utilized, developing the communication streams during the pilot, and defining the project goals. The main goal of the project was to create a viable DDA process for the Alliance, not to create a perfected program from the onset. The full descriptions of the work involved at the early stages can be found in the minutes and progress reports of the demand driven acquisition pilot web pages and the link given above will provide access to these documents. Susan Hinken \& Emily McElroy wrote a very good overview of the project development plan in the June 2011 issue of Against the Grain.2

The pilot project went live via the libraries on 1 July 2011. YouTube videos were developed to introduce and train staff at the participating libraries targeted to public services staff and also to those working on the technical side of loading records. MS Word document guides were also posted to the DDA pilot web pages. In the first three months of the pilot, only $4 \%$ of the budget was expended. The original trigger for an ebook purchase was set at ten short term loans prior to purchase. After the September meeting of the implementation team where the decision was made to change the threshold of ebook purchases to five short term loans, expenditures began to 
increase. Although the pilot was originally planned for six months, the Alliance Council of library directors made the decision in December 2011 to extend the pilot through June 2012 in order to have the best data available to determine if the demand driven program would be adopted by the Orbis Cascade Alliance as an ongoing program. There have also been minor tweaks here and there to workflow as concerns and issues have been raised by participating libraries.

To date, the Orbis Cascade Alliance DDA pilot project can be seen as one of the more successful demand driven pilot projects undertaken by a consortium. The Alliance DDA implementation team performed quite a bit of research and investigation in setting up the model they have used in order to avoid situations such as the one experienced by the Ontario Council of University Libraries, in which $\$ 150,000$ was spent in 9 days. 3 The Alliance pilot was designed to avoid such rapid spend-down, allowing time for member libraries to become accustomed to this new acquisitions model.

To get a sense of what the implementation team members feel about the pilot project, ten questions were asked of the team, EBL representatives, and YBP representatives. Here are the questions and responses received from the implementation group members:

Jill Emery: What were your hopes for the demand driven acquisitions project when you first began the pilot project?

Xan Arch: I hoped that this could help jumpstart ebook adoption in the smaller schools that might have less experience with the format.

James Bunnelle: I came on board at the implementation stage but was kept abreast of what was going on by being on the CDMC (the Alliance collection development and management 
committee) steering team with Emily and Susan, and others. My main hope was that the project would lay the foundation for a new type of cooperative ebook collection that could be centrally funded and easily accessible by all members. More to the point, I felt the more that ebook collections grew at the local level in individual libraries, the more we undermined the types of cooperative collection development projects taken on by the CDMC. Building up robust, locked-down localized ebook collections is totally counterproductive and hurts the Alliance's consortial leveraging power.

Linda Di Biase: What excited me was expanding the vision of a "collective collection" shared by all consortium members beyond the print world to the electronic world. Previously, the Alliance functioned as a buying group for e-resources, saving participating libraries money. However, these e-resources could not be shared with other Alliance libraries. So we had two models going: one for print, which (by means of a shared catalog, a common preferred approval vendor, and duplication guidelines) emphasized collective decision-making, at least in the ideal; the other, which focused exclusively on individual library needs.

Susan Hinken: My biggest frustration with expanding our local library's collection of ebooks has been the inability to share with other Alliance libraries. It contradicts both the idea of the Alliance collection and the goal of sharing resources among members. I was hoping that we would either develop a preliminary model through the pilot to share ebooks, or learn what we needed to do differently to help create an environment where these resources could be shared. My library did not have an individual DDA plan so I also hoped, by seeing the model in action, to understand better the user's role in this form of collection development and if we could adopt it locally. 
Emily McElroy: This project demands flexibility from everyone involved since we were the first consortium of this size to move in this direction. As a result, I limited my hopes to the original charge provided by the Alliance council. Along with our vendor partners, the DDA team implemented a broad subject profile to provide relevant content for a diverse group of libraries. From the very start of our negotiations, we were clear with EBL on how important it was to have a solid group of publisher participation. As we moved into the implementation stage, the team developed a better understanding of the complexities with the publisher marketplace. Our hopes were somewhat dashed when we learned that several large publishers were unwilling to participate in this type of program. From a financial perspective, I wanted our funds to last through the middle of the fall semester, and for the Alliance to eventually own content.

Sadie Williams, Kari Paulson \& Alison Bobal from EBL : EBL's main goal was to explore a shared access DDA model. We hoped to better understand what would happen when a DDA purchasing model was put into a shared access framework. We hoped to gain some insight and data on usage and acquisition behavior. We also wanted to learn what workflows and functionality would be needed to support consortia DDA access and purchasing, and to develop the tools needed to make this model a more robust and better experience for libraries and end users.

Additionally, we wanted to closely look at the viability and sustainability of this model in the future and provide data and analysis to publishers to help them make more informed decisions on whether or not to include their content in such a model. We hope that the model and the data coming out of the pilot will prove to be a powerful tool for libraries and publishers, useful to building both individual and shared collections. 
John Elliott, Joan Thompson, and Barbara Kawecki from YBP: Our goal was to support the development, implementation, and coordination of the project so that it complemented existing print and ebook purchases via approval, firm order, or standing order by Alliance member libraries. Additionally, we sought to provide the ebook team with the print purchase data necessary to determine the true level of duplication within the Alliance over a set period of time. These data were critical in establishing a baseline for the ebook team's negotiations with publishers and aggregators on a fair price multiplier.

Jill Emery: Other consortia DDA projects have not been successful, what did you learn from those experiences to make this one more robust?

Xan Arch: We learned to track the progress of the pilot carefully, to be open to changes in the pilot format along the way, and to emphasize communication with consortium libraries to help ease the impact of such a new service.

James Bunnelle: I don't think it was ever explicitly articulated, but since many of us on the team had seen the same trainwreck in MS Powerpoint presentations from librarians with shaky hands, we intuitively approached the funding model, and particularly the short-term loan trigger, with caution and a good deal of anxiety. We sort of planned for a worst-case spending scenario and scaled up as needed. Despite the work that was involved post launch, it was still preferable to the alternative of burning through hundreds of thousands of dollars over a midterm weekend.

Linda Di Biase: The Alliance has an excellent track record of collaboration, particularly in the area of collection development (the area with which I am most familiar.) There is a lot of trust among the collection officers at the Alliance institutions, many of whom have worked together over the years on the Alliance's Collection Development and Management Committee. With 
YBP's assistance, we have also been collecting data for some time regarding our print purchases, and we were able to bring that data to bear when we were negotiating a multiplier for e-book purchases. We were also fortunate to partner with a company that has been doing DDA for some years with libraries of various sizes. As a result they had data to bring about the likely consequences of decisions we might make concerning the size of the content offered, the purchase trigger, etc. We were clear from the start that we wanted to make our money stretch at least six months, so we were careful not to make too large a pool of titles, too low a trigger, etc. We also knew we could make changes mid-course, which indeed we have done.

Susan Hinken: I feel we recognized quite early that a partnership with our vendors would be essential to move forward. I also think we were especially mindful of trying to establish both a collection that would appeal to various types of libraries and develop a use/spending model that would spend the money down over several months. We spent a great deal of time analyzing data and defining the original threshold for purchase, trying to come up with a number that would help us spend the funds over a long enough period of time to give all participants an opportunity to use titles within the pilot and build a useful body of evaluative data.

Emily McElroy: The most important lesson was that we needed a flexible model that would work for a consortium of our size. From the first meeting we had with different vendors, I felt confident in EBL's approach to our project. Their short-term loan model allows a library or consortium to expend funds in a more thoughtful way. If we had proceeded with a model that generated costs at the first view or browse after five minutes then we would have met the same fate as other projects. We also involved YBP from the very beginning, which was not something 
that happened with other projects and I was fairly confident that our project was starting from a stronger foundation than other projects because of our history in collaborative projects.

Sadie Williams, Kari Paulson \& Alison Bobal from EBL : It is very important from the outset to have a good understanding of the access model and how the DDA structure will affect expenditures. Purchase triggers should be well defined, transparent and flexible. As a library or consortium learns how their program progresses, there should be opportunities to make adjustments.

A second important piece for us in getting the project set up was ensuring that the expectations for the group were well defined and that all participants had an aligned view of goals and expectations. Consortia should also set enough time aside before the pilot begins to outline workflows in as much detail as possible to avoid surprises down the line. This was something I believe Orbis Cascade Alliance has done particularly well.

John Elliott, Joan Thompson, and Barbara Kawecki from YBP: Our goal was to support the development, implementation, and coordination of the project so that it complemented existing print and ebook purchases via approval, firm order, or standing order by the Alliance member libraries. Additionally, we sought to provide the ebook team with the print purchase data necessary to determine the true level of duplication within the Alliance over a set period of time. These data were critical in establishing a baseline for the ebook team's negotiations with publishers and aggregators on a fair price multiplier.

Jill Emery: At this point in the demand driven acquisitions pilot project, do you feel the project is proceeding in the way you hoped it would? 
Xan Arch: Yes, overall it is proceeding well.

James Bunnelle: Well, I still wouldn't consider it large enough. I would love to see all of the funds that the Alliance libraries spend on ebooks going into a centrally funded DDA model so that we are not spending money on content that cannot be shared, especially if this ebook content is firm ordered by selectors and has the poor "circulation" rates so often synonymous with justin-case content.

Linda Di Biase: I am mostly satisfied with the project's progress. We knew there would be bumps in the road - but we made adjustments and never lost our focus.

Susan Hinken: From the end user perspective, yes. I think the use data indicates that the team was successful in developing an approval plan that would identify titles of interest to the Alliance users (although the limited number of publishers had a large role in parameters of the plan). Overall, librarians in member libraries have been upbeat, especially considering the additional volume of work that many of them have had to undertake, some technical glitches, and the uneven quality of some cataloging records.

Emily McElroy: Yes. We have met the original charge given to us from the Alliance Council. We own content that is shared by all Alliance libraries. We are providing content that is used from the community colleges to the largest ARL for a reasonable value. As a representative from a more specialized institution, I am pleased with the usage from our users. Our data demonstrates that all of our users have access to content that would not otherwise have been shared in electronic format. There are some areas of this project that have not proceeded as I would have liked. We faced technical challenges that were unanticipated. It took us awhile to 
reconsider earlier decisions from how we handled records, the number of short-term loans and the volume of records. While it was frustrating or confusing to people that we changed parts of the program, we needed the flexibility to adjust the program based on the data or workflow problems that did not improve with time. I am surprised that there is still some confusion surrounding the purpose of this project and what this means for long-term success. Fortunately, the DDA team has focused on our charge and not been sidelined by small issues.

Sadie Williams, Kari Paulson \& Alison Bobal from EBL : From the EBL perspective, we are very happy with how the project is proceeding. The project is on track in terms of access and expenditure. There has been excellent communication between EBL and the group that has allowed us to react to trends in spending and adjust the model as needed. The feedback we receive from participating libraries has been very positive.

John Elliott, Joan, Thompson, and Barbara Kawecki from YBP: We are very pleased with the results of the project thus far. The flexibility of the model and the ongoing communication and management of the pilot between member libraries, the ebook team, EBL, and YBP is delivering great value for the Orbis Cascade Alliance.

Jill Emery: It seems like all demand driven acquisitions projects are only as successful as each participating organization, what area do you foresee needing the most tweaking as this would move forward from a pilot project into a regular program for the Alliance libraries?

Xan Arch: Mostly I feel like it needs to settle from a changeable pilot into a set process that everyone can rely on. That will include an established funding model, a designated group of people to manage the process over time, and a clear idea of where the process is heading over the next few years. 
James Bunnelle: Definitely the funding model. The team is in the process of rethinking that now. This will be a challenge and one of the real linchpins for its ongoing survival.

Linda Di Biase: The whole technical services piece continues to need attention. We need OCLC's assistance, for instance, to get the KnowledgeBase working as we'd hoped it would. We also need to continue to work on getting everyone on board with the concept of DDA and what we're trying to achieve with this program. For instance, at least for a time, one library was only adding to its catalog those titles that had been purchased outright, and not all the DDA titles.

Susan Hinken: Various members have voiced different concerns but I believe to make this a robust program more publishers must be brought into the mix, the effort to automate workflows around record loads and deletions should be continued, and member libraries need to see the type of data that would demonstrate the value to the Alliance and individual libraries, including use data and return on investment.

Emily McElroy: My hope is that every library takes a close look at the data we provide on a weekly or monthly basis and our return on investment data in the final evaluation. My hope is that this data continues to decrease the resistance to demand-driven acquisitions or Alliance projects that move us towards "one collection." What this project has demonstrated is the need for ongoing communication of our strategic agenda and what it means to be a member of the Alliance. It has also demonstrated that even a project as small as this requires an investment of staff time, patience with the process, and that workflow matters. We really need everyone to remember the big picture of what this project represents and not that a title here or there seem like an odd choice for our users to access. We also need the workflow between OCLC and 
vendors to improve since this is a major area of dissatisfaction with the project. As more consortia proceed with demand-driven projects, I hope we see improvements in workflow and enhancements to the discovery process.

Sadie Williams, Kari Paulson \& Alison Bobal from EBL: In the future I think EBL can offer more robust reporting tools, and tools in the administration interface as well as additional management tools around shared collection building.

John Elliott, Joan Thompson, and Barbara Kawecki from YBP: The continued use of and improvement to consortial reporting tools in GOBI will help the processes established during the pilot to become even further integrated into the regular workflows of member libraries. Jill Emery: After your presentation on the project at the Charleston Conference 2011, one attendee made the remark that the pilot was "not successful" because of the limited number of sales achieved by the participating publishers. How would you respond to this critique? [EBL \& YBP participants]

Sadie Williams, Kari Paulson \& Alison Bobal from EBL: The goal of the pilot was not to simply purchase titles but to balance purchases with access to as many titles as possible within a set budget. As far as sales achieved by participating publishers, the expenditures and revenues are on track for what was projected for the pilot.

It is important to remember that you do not just flip a switch on a DDA program and start purchasing. The model is organic and grows and develops over time as use accumulates and demand trends emerge. Whether a shared or individual program, DDA needs the benefit of time to fully understand outcomes.

One of the great successes for this pilot was that group very quickly addressed the initial low volume of transactions and adjusted the model so that moving forward was in align with their 
expectations.

John Elliott, Joan Thompson, Barbara Kawecki from YBP: Clearly it is still too early in the pilot to determine the success or failure of the project and such a determination is entirely subjective in any case. Each DDA project, individual or consortial, has its own goals. Essentially, these goals come down to ownership of content vs. access to content. It is important to keep in mind that one of this project's goals is to provide the Alliance patrons with access to content, not simply to purchase as much content as possible, as quickly as possible. Through what is likely the midpoint of the project, 4,881 titles had been accessed 22,342 times (this includes browsing) by 35 of the 36 members participating. That is a tremendous amount of content accessed for the funds spent. Additionally, as the panel in Charleston explained during their presentation, one of the well-planned aspects of the project is the evaluation report scheduled to be done at the conclusion of the pilot. This comprehensive evaluation will be made available so that any interested consortia and/or individual library can determine if a similar pilot would be of interest. Jill Emery: At the last implementation meeting, the decision was made to make this project an "ownership" model; do you think this decision has helped develop a more viable service for the Alliance members? [librarian participants]

Xan Arch: That was decided early on in the process. It does mean that we set the purchase trigger lower so that more content is ultimately owned by the Alliance, but otherwise the model is the same and whether we end up owning a title or just borrow it a few times depends on the demand.

James Bunnelle: Yes, I think so. For libraries, the psychology of ownership, especially for monographs, is so core to what they are and the services they provide, even a rationale argument for leasing would get buried in the end. The wording was in the initial charge from the executive 
council that ownership at the end of the pilot was important. Therefore, the team kept that in mind throughout the process, including the setting of the short-term-loan threshold. Everyone felt that a completed pilot with no tangible pool of content would be a bad thing. And it's just easier to get more traditional collection managers on board with the ownership approach.

Linda Di Biase: I think it is a misstatement to suggest that we changed the project to emphasize ownership. Ownership was envisioned from the start, as indicated by the ebook team's final report (October 1, 2010) to the Alliance board. Though in setting up the pilot we benefitted from EBL's data from its varied academic customer base, there really was not data for a consortial project like ours. We wanted to emerge from the pilot with a permanent shared collection and felt we needed to both expand the content and tweak the purchase trigger to achieve this end. However, we never lost sight of the importance of demonstrable use (as evidenced by short-term loans) in determining which titles we would ultimately purchase.

Susan Hinken: I do, particularly since several of the Alliance members had voiced concern about the pace at which funds were spent and the lack of purchased titles. I also hope that the ownership model will be an element in bringing more publishers into the pilot, if they can see that participation can translate into income streams.

Emily McElroy: We actually had an ownership model from the beginning.

Jill Emery: The advice from the implementation team is not to market the pilot project at participating institutions; do you think this is still limiting the variables for the overall evaluation of the project? [librarian participants] 
Xan Arch: I think it was helpful for the pilot since it did limit the variables that might distinguish different participating libraries, but I doubt that we will continue without some marketing. Participating libraries would like to market this pilot and have suggested this to the team repeatedly.

James Bunnelle: This is really a philosophical question and there is disagreement. There's also different levels of this, of what one defines as marketing. I don't consider a library homepage news item saying "We now have access to more ebooks" to be marketing. If you direct users to the content in a more concerted way, then I think that crosses a line. I feel that active marketing of a project whose entire purpose is to provide access to content on an as-needed basis is sort of ridiculous. In DDA, the metadata is the advertising. If that is solid, then the usage will follow if the need is there. Anything else could just generate impulse hits, with no driving research need, that might skew evaluation results. But yeah, there's disagreement in the Alliance on this one.

Linda Di Biase: I think it is important for the pilot not to have too many variables that may make it difficult to do assessment, and we decided that marketing (or non-marketing) was something we wanted to hold constant. For large libraries with already significant ebook holdings and user experience, marketing is really a non-issue. However, I can see that going forward smaller libraries may find value in marketing, and we should plan ways to accommodate that.

Susan Hinken: No. We had a discussion among the librarians at my library about marketing the pilot and it reinforced my sense that the pilot could not have been effectively marketed to users. I think some of the concern about marketing was driven less by user needs and experiences and more by the need for libraries to present themselves as proactive campus entities. I think this 
type of on campus marketing is importan,t but in this case I don't think restricting marketing will have affected use or limits the evaluation of the pilot.

Emily McElroy: I really do not think so. In some ways, I find it more fascinating to see how users are finding content without any marketing. We felt that we already had enough variables to consider in our evaluation through the different discovery options. Each library has a different definition for how they market products so it added a new layer of complexity. The debate surrounding whether or not to market the project to users demonstrated how different our libraries approach resources. For some libraries, they would not consider marketing a relatively small number of titles to users while other libraries do not care about the size of the collection. Some libraries really integrate e-book holdings in their bibliographic instruction or communication with faculty and staff and other libraries feel that discovery of ebooks already occurs through regular discovery options. I am not sure if the difference between libraries is really based on library size. I suspect it relates more to the size of a library's ebook collection size and how different libraries use their faculty to select books. Through other Alliance projects, we know that some libraries rely almost exclusively on their faculty to select print and electronic books. I could see how those libraries would want to market this new resource to their faculty. I would not think of reaching out to the faculty at my institution because they already expect electronic content through regular discovery tools. As we move into a program, we will leave it up to each library to integrate this content in their methods for marketing.

Jill Emery: If there was one thing you would have done different from the beginning of the pilot project, what would that be? [all participants] 
Xan Arch: It would have been best to start the pilot with a simpler process that satisfied the majority of the participants, rather than a complicated process that worked for every library. We could have then moved toward a process that worked for everyone.

James Bunnelle: Maybe more time to get more publishers on board, or to brainstorm on other ways to approach that problem. EBL worked hard on that but the pool is still somewhat modest.

Linda Di Biase: This is hard to answer. We thought we were doing a good job of communicating, to the Alliance executive committee and library directors, to DDA library liaisons, and others, but misunderstandings along the way seem to point to the truism that you can never communicate too much.

Susan Hinken: I would have brought OCLC into the conversations earlier. A great deal of time and effort was spent on issue of access, record loading and use of the Knowledge Base. Perhaps earlier conversations with OCLC might have reduced some of that time.

Emily McElroy: A group of us presented at the 2011 Charleston Conference on all of the lessons we learned during the implementation. Some attendees said we were too hard on ourselves because we were starting with few models. I agree but I would have approached communication in a different way. I find it surprising how many libraries still do not know about some of the tools available to them. We tried sending out regular emails to a list of designated representatives, along with a website that offered an FAQ and training materials. It was not enough or did not reach all of the appropriate people. At the same time, we could not control the communication from library representatives to their colleagues. Even at my own institution, people do not remember basics of the program and I am the chair of the project. Looking back, I 
would have created a regular distribution list for anyone interested with weekly updates on all aspects of the program.

Sadie Williams, Kari Paulson \& Alison Bobal from EBL: EBL's goal from the start was to learn from the pilot and I think that we have done just that. The task group took a lot of time in the beginning to think about workflows and to plan for aspects of the pilot that may need revision along the way. This helped all of us avoid nasty surprises. We feel that the project was well thought out and allowed for ample planning and lead-time for implementation and development. The timeframes were realistic and flexible enough to allow the time to build necessary tools I don't feel like we would have done anything differently from the beginning of the pilot.

John Elliott, Joan Thompson, and Barbara Kawecki from YBP: Encouraging more publishers to participate in similar programs. The project represents the first experience for some Alliance member libraries of working with ebooks through an aggregator's platform. Also, we noticed that a few smaller libraries began purchasing ebooks for the first time. The DDA pilot appears to have increased ebook use and purchasing.

Jill Emery: Currently, there are a fixed number of publishers participating in this pilot project, how can the project be marketed to gain other publisher participation if this becomes adopted by the alliance? [EBL \& YBP participants]

Sadie Williams, Kari Paulson \& Alison Bobal from EBL: Being able to back up proposals to publishers with data is key. Having the original data from YBP about overlap of acquisitions in print was helpful in the initial negotiations with publishers. Combining that data from print acquisitions with the statistics and data from this project should provide a wealth of information that can be used answer publisher questions and build a case for marketing the program to a 
wider group of publishers.

John Elliott, Joan Thompson, and Barbara Kawecki from YBP: DDA is rapidly moving from being an isolated trend to being an integral part of many libraries' collection development strategies. This project can be marketed as a way for publishers to see incremental sales growth over their current print sales to the Orbis Cascade Alliance as a result of the price multiplier and additional revenue from short-term loans. Further, the project represents the first experience for some Alliance member libraries of working with ebooks through an aggregator's platform. As a result, the publishers are reaching a wider market for their ebooks. And it appears that the DDA pilot has increased ebook use and purchasing within this group of libraries.

Jill Emery: What do you think has been most successful about the demand driven acquisitions pilot project? [all participants]

Xan Arch: I feel that we communicated well with participating libraries and our training was thorough and well received.

James Bunnelle: That a diverse group of academic libraries across two states, with vastly different missions, financial situations, and FTEs, could come together and think collectively about sustainable solutions for the common good.

Linda Di Biase: We have demonstrated that a large and diverse consortium, operating exclusively on member contributions and lacking central funding, can nevertheless venture into new territory in partnership with committed vendors. A pilot's success is not defined by the total absence of problems, but in anticipating those problems to the extent possible, learning from them when they inevitably occur, and taking steps to address them promptly. This we have achieved, and I am proud of our achievement. 
Susan Hinken: I think the pilot has most successfully demonstrated the importance of creating partner relationships between libraries and vendors, positioned the Alliance as a leader in library cooperation and furthered the conversation about how to fit eBooks into that cooperative environment.

Emily McElroy: We are purchasing content that is shared by all of the Alliance libraries. Almost five years ago, I attended an Alliance meeting of collection development librarians. Different people expressed concerns on how our consortium would continue meeting the needs of our users as each library purchased e-books that could not be shared within the Alliance. While this is only one solution, we have made progress in addressing this problem. I am also proud of how this project has helped other consortia or libraries considering a demand-driven program. Along with others who handle inquiries, I always present a realistic view of what has or has not worked. The marketplace has changed so much since we started exploring this project. As more consortia move in this direction, we will benefit from the different approaches towards demand-driven acquisitions or other purchasing models for e-books. While our success has always seemed premature to me, I also know that other consortia find the selection and implementation phase daunting. The feedback we have received from other groups indicates that we successfully managed the selection and implementation despite the obstacles we faced.

Sadie Williams, Kari Paulson \& Alison Bobal from EBL: The collaboration and organization among the library participants as well as the vendors involved has been key for this project. From the beginning everyone communicated and worked together to make the project a successful one.

Furthermore, the management of this project by the ebook implementation team was exceptional. 
Having a well thought out plan, and an outline of expectations and goals are important for the success of any project. The Alliance and the ebook implementation team took enough time at the outset to define the requirements for the project and work through details. This avoided surprises along the way and provided a framework to understand what changes may have been needed as they moved forward.

Finally, I think the group was successful in taking the time to fully understand and outline the workflows involved and ensure that participants were well educated.

John Elliott, Joan, Thompson, and Barbara Kawecki from YBP: The care and attention that has been paid to the planning and ongoing management of the project combined with the collaboration with vendor and aggregator partners have all been aspects that are true highlights of this pilot.

Jill Emery: I want to thank all of the members of the Orbis Cascade Alliance demand driven acquisitions pilot project implementation team for taking the time to respond to these questions and for providing further insight into this exciting program. 
References:

1. Demand Driven Acquisitions Pilot, Orbis Cascade Alliance web site: http://www.orbiscascade.org/index/demand-driven-acquisitions-pilot referenced on 6 February 2012.

2. Hinken, Susan, and McElroy, Emily. "Pioneering Partnerships: Building a DemandDriven Consortium eBook Collection.” Against the Grain, V. 23, no.3 2011 (June)

3. Electronic Resources \& Libraries 2011 Conference. "16 Schools, \$150,000 and 9 days: Experimenting with the Patron Driven Acquisition Model in a Consortial Environment" Presented 28 February 2011. http://www.electroniclibrarian.com/past-conferences/2011conference referenced on 6 February 2012. 